\title{
Efeito da adição de proteína do soro do leite como substituto do trigo na formulação de bolos sem adição de açúcar
}

\author{
The effect of the addition of whey protein as a substitute for wheat in the development \\ of cakes with no added sugar
}

\begin{abstract}
Jéssica Pazzaro Soares', Gleicyane de Almeida Marques², Camila Soares de Magalhães², Aline Bravim Santos²,

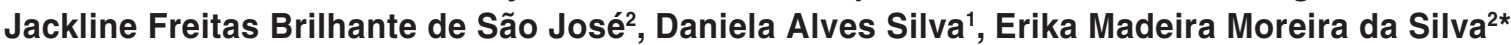

1 Universidade Federal do Espírito Santo (UFES), Centro de Ciências da Saúde, Departamento de Educação Integrada em Saúde, Laboratório de Técnica Dietética do Curso de Nutrição, Vitória/ES - Brasil

2 Universidade Federal do Espírito Santo (UFES), Centro de Ciências da Saúde, Programa de Pós-graduação em Nutrição e Saúde (PPGNS), Vitória/ES - Brasil
\end{abstract}

\section{*Corresponding Author}

Erika Madeira Moreira da Silva, Universidade Federal do Espírito Santo (UFES), Centro de Ciências da Saúde, Programa de Pós-graduação em Nutrição e Saúde (PPGNS), Avenida Marechal Campos, 1468, Maruípe, CEP: 29040-090, Vitória/ES - Brasil, e-mail: erika.alimentos@gmail.com

Cite as: The effect of the addition of whey protein as a substitute for wheat in the development of cakes with no added sugar. Braz. J. Food Technol., v. 21, e2016190, 2018.

Received: Dec. 21, 2016; Accepted: Aug. 30, 2017

\section{Resumo}

A proteína do soro do leite (PSL) é um produto da fabricação de queijos, que apresenta elevado valor nutricional e atributos funcionais. Sua utilização em produtos de panificação favorece aspectos físicos, como a emulsão e a capacidade de estabilização, além de melhorar características sensoriais. O presente estudo teve como objetivo elaborar bolos sem adição de açúcar, utilizando-se a PSL como substituto do trigo, bem como avaliar suas características físicas, químicas, sensoriais e microbiológicas. O efeito da adição de PSL e margarina em bolos foi avaliado por meio de um delineamento central composto rotacional de segunda ordem. Os tratamentos selecionados foram avaliados por meio de análise sensorial e caracterizados quanto à composição centesimal, além de se proceder à avaliação microbiológica após 15 dias de armazenamento. A adição de até $11,98 \mathrm{~g} / 100 \mathrm{~g}$ de margarina influenciou de forma expressiva na redução da altura dos bolos. O tratamento com teor intermediário de PSL (30 g/100 g) e menor teor de margarina $(6,72 \mathrm{~g} / 100 \mathrm{~g})$ obteve melhor aceitabilidade e, quando comparado ao controle, maior conteúdo de proteínas. As condições microbiológicas foram satisfatórias, atendendo à legislação vigente, mesmo após 15 dias de armazenamento.

Palavras-chave: Proteína do soro do leite; Lipídios; Panificação; Composição de alimentos.

\section{Abstract}

Whey protein (WP) is a product of cheese making which has high nutritional value and functional attributes. Its use in bakery goods favours the physical aspects as well as the emulsion and stabilization capacity and improves the sensory characteristics. The aim of this study was to replace wheat by whey protein in sugar free cakes and evaluate their physical, chemical, microbiological and sensory characteristics. The effect of adding whey protein and margarine on cakes were evaluated using a second order central compound rotational design. The selected treatments were evaluated by means of a sensory analysis and characterized according to their proximate composition and a microbiological evaluation after fifteen days of storage. The addition of up to $11.98 \mathrm{~g}$ of margarine per $100 \mathrm{~g}$ had an important influence on the reduction in cake height. The treatment with an intermediate WP content $(30 \mathrm{~g} / 100 \mathrm{~g})$ and a lower margarine content $(6.72 \mathrm{~g} / 100 \mathrm{~g})$ showed better acceptability and a higher protein content when compared to the control cake. The microbiological conditions were satisfactory, conforming to current legislation, even after fifteen days of storage.

Keywords: Whey protein; Lipids; Bakery products; Food composition. 


\section{Introdução}

Os bolos têm ocupado a segunda posição entre panificados mais consumidos, perdendo apenas para o pão (GOHARA et al., 2014). Segundo dados da Associação Brasileira das Indústrias de Massas Alimentícias (ABIMAPI, 2016), o consumo per capita de bolo industrializado no Brasil tem sido de 0,16 kg/ano, ocupando o oitavo lugar no ranking mundial de vendas.

Os ingredientes básicos para a elaboração de um bolo são farinha, gordura, ovos, açúcar, fermento e um líquido, sendo que, se alteradas as proporções destes ingredientes, pode-se produzir diferentes preparações (KÖVESI et al., 2007).

Seguindo a tendência atual, observa-se a crescente preocupação com a saúde e a estética corporal, fazendo com que o consumidor busque, no mercado, produtos que sejam nutricionalmente saudáveis, bem como sensorialmente agradáveis. Com isto, surgem a necessidade e o interesse da indústria em inserir e/ou substituir determinados ingredientes, objetivando aumentar o valor agregado de produtos alimentícios processados (SILVA, 2011; VOORPOSTEL et al., 2014).

A proteína do soro do leite é um produto da fabricação de queijos economicamente importante, que é utilizado como um ingrediente na indústria alimentar devido ao seu elevado valor nutricional e aos seus atributos funcionais. Além disso, tem um elevado potencial biológico, resultante do seu conteúdo de aminoácidos essenciais, em particular leucina e lisina, sendo, também, uma boa fonte de metionina e cisteína (OLIVEIRA et al., 2012).

Os bolos são produtos bem aceitos pelos consumidores e seus ingredientes podem ser substituídos com facilidade. Assim, se torna um desafio interessante estudar formas de melhorar sua qualidade nutricional sem que a propriedade sensorial seja prejudicada. Neste caso, a proteína do soro do leite apresenta-se como potencial substituto parcial ou total da farinha de trigo.

$\mathrm{Na}$ elaboração de produtos de panificação, o enriquecimento com proteína de soro de leite melhora a emulsão e a capacidade de estabilização (LAM; NICKERSON, 2015). Além disso, melhora o sabor, a textura, e a cor, além de aumentar o valor nutricional (ZAVAREZE et al., 2010).

Conforme o estudo de Esteller (2004), nos produtos de panificação, como o bolo, a proteína concentrada do soro de leite pode ter aplicabilidade como substituto de gordura em produtos com teor reduzido desta. Uma das vantagens de utilização das proteínas do soro do leite é que estas se ligam aos componentes aromáticos; porém, essas proteínas são sensíveis a altas temperaturas (PINHEIRO; PENNA, 2004). Assim, com o conhecimento das propriedades das proteínas do soro do leite, optou-se pela variação do teor de margarina, para se estudar a contribuição dessas duas variáveis (PSL e margarina) nas características dos bolos.

Deste modo, o objetivo deste estudo foi elaborar bolos sem adição de açúcar contendo proteína do soro do leite (PSL), bem como avaliar o efeito da adição deste ingrediente (em substituição ao trigo) e do teor de margarina nas características referentes às medições desses produtos. Além disso, avaliar a aceitabilidade e analisar características químicas e microbiológicas das formulações escolhidas no teste sensorial.

\section{Material e métodos}

A matéria-prima principal utilizada foi a proteína de soro de leite (PSL), cedida pela empresa Probiótica (São Paulo-SP). O edulcorante sucralose em pó foi fornecido pela empresa Linea (São Paulo-SP). Os demais ingredientes utilizados para a elaboração do produto foram adquiridos no comércio local (Vitória-ES). Os experimentos de elaboração dos bolos foram conduzidos no Laboratório de Técnica Dietética do Centro de Ciências da Saúde da UFES e os demais experimentos foram conduzidos nas dependências laboratoriais do referido Centro.

\subsection{Delineamento experimental}

Foi utilizado o delineamento composto central rotacional de segunda ordem (BOX; DRAPER, 1987), com a finalidade de estudar o efeito das diferentes proporções da PSL (15,86 a 44,14 g/100 g) e margarina $(6,72-11,98 \mathrm{~g} / 100 \mathrm{~g})$ nas medições dos bolos. As proporções de PSL foram calculadas em relação à substituição do trigo. As proporções de margarina foram calculadas tomando, como base, o valor total da massa. As variáveis foram estabelecidas em cinco níveis codificados com quatro repetições no ponto central, quatro variáveis no ponto axial e quatro fatoriais, totalizando 12 ensaios (Tabela 1). O ponto central proposto foi obtido por meio de experimentos conduzidos em testes preliminares e informações disponíveis na literatura, por meio de uma ampla revisão bibliográfica. Na etapa de testes preliminares, os principais objetivos foram: inserir concentrações máximas de PSL em substituição ao trigo, bem como testar distintas concentrações de margarina, a fim de ajustar as formulações com o mínimo possível deste componente. As variáveis foram estudadas em três níveis codificados em $(-1,0,+1)$. Esse delineamento apresentou também dois níveis de variáveis axiais, que são codificados como $(-\alpha)$ e $(+\alpha)$, considerando-se $\alpha=1,41$.

\subsection{Formulação dos bolos}

Os demais ingredientes utilizados para a preparação dos bolos foram: farinha de trigo, ovo, edulcorante sucralose em pó (Linea ${ }^{\circledR}$ ), leite desnatado, fermento químico e sal. Todos os ingredientes, exceto o fermento químico, foram homogeinizados em batedeira (Arno), por três minutos. 
Efeito da adição de proteína do soro do leite como substituto do trigo na formulação de bolos sem adição de açúcar Soares, J. P. et al.

Tabela 1. Resultados das medições dos bolos elaborados com diferentes proporções de proteína do soro do leite (PSL) e margarina.

\begin{tabular}{|c|c|c|c|c|c|c|c|c|c|c|}
\hline Tratamentos & $X_{1}$ & $X_{2}$ & $\begin{array}{c}\text { PSL } \\
(\mathrm{g} / 100 \mathrm{~g})\end{array}$ & $\begin{array}{c}\text { Margarina } \\
(\mathrm{g} / 100 \mathrm{~g})\end{array}$ & Altura & Diâmetro & $\begin{array}{c}\text { Volume } \\
\text { Aparente } \\
\text { (mL) }\end{array}$ & $\begin{array}{c}\text { Volume } \\
\text { Específico } \\
\left(\mathrm{mL} \cdot \mathrm{g}^{-1}\right)\end{array}$ & $\begin{array}{c}\text { Fator de } \\
\text { Expansão }\end{array}$ & $\begin{array}{c}\text { Rendimento } \\
(\%)\end{array}$ \\
\hline 1 & -1 & 1 & 20 & 11,11 & 1,89 & 0,94 & 176,62 & 3,04 & 0,98 & 80,55 \\
\hline 2 & -1 & -1 & 20 & 7,69 & 2,10 & 0,92 & 183,33 & 3,18 & 0,92 & 80,84 \\
\hline 3 & 1 & 1 & 40 & 11,11 & 1,97 & 0,91 & 183,33 & 2,63 & 0,89 & 86,38 \\
\hline 4 & 1 & -1 & 40 & 7,69 & 2,65 & 1,01 & 185,11 & 2,85 & 0,92 & 85,97 \\
\hline 5 & $-1,41$ & 0 & 15,86 & 9,4 & 2,24 & 0,94 & 153,34 & 2,57 & 0,88 & 84,50 \\
\hline 6 & 1,41 & 0 & 44,14 & 9,4 & 2,70 & 0,95 & 176,67 & 2,65 & 0,77 & 84,31 \\
\hline 7 & 0 & $-1,41$ & 30 & 6,72 & 3,11 & 0,93 & 170,55 & 2,58 & 0,85 & 86,47 \\
\hline 8 & 0 & 1,41 & 30 & 11,98 & 2,37 & 0,96 & 158,31 & 2,24 & 0,80 & 89,36 \\
\hline 9 & 0 & 0 & 30 & 9,4 & 2,36 & 0,83 & 220,12 & 3,78 & 0,90 & 83,97 \\
\hline 10 & 0 & 0 & 30 & 9,4 & 2,38 & 0,91 & 180,55 & 2,88 & 0,86 & 85,48 \\
\hline 11 & 0 & 0 & 30 & 9,4 & 2,32 & 0,87 & 160,00 & 2,56 & 0,81 & 83,92 \\
\hline 12 & 0 & 0 & 30 & 9,4 & 2,35 & 0,97 & 163,30 & 2,51 & 0,88 & 87,47 \\
\hline
\end{tabular}

$\mathrm{X}_{1}$ : variável codificada para proteína do soro do leite; $\mathrm{X}_{2}$ : variável codificada para margarina.

Após este procedimento, foi adicionado o fermento químico, o qual foi misturado manualmente. Porções com cerca de $290 \mathrm{~g}$ de massa de bolo foram distribuídas em fôrmas de cupcakes previamente forradas com papel manteiga, levadas ao forno pré-aquecido por 15 minutos e assadas durante cerca de 30 minutos a $185^{\circ} \mathrm{C}$. Em seguida, o forno foi desligado e os bolos, retirados.

\subsection{Avaliação das medições}

Seis bolos de cada preparação, provenientes de uma mesma fornada, foram analisados, de acordo com o método 10-50D da American Association of Cereal Chemists (AACC, 2000). As medidas de peso foram determinadas antes e após a cocção, em balança de precisão Marte (ML6K - $6 \mathrm{~kg} \times 0,1 \mathrm{~g})$. O diâmetro e a altura dos bolos foram determinados com paquímetro Vernier Caliper $(150 \times 0,05 \mathrm{~mm})$, sendo calculada, para cada variável, a razão entre as medidas pós e pré-cocção. O fator de expansão foi calculado como a razão entre os valores de diâmetro e altura. O rendimento foi calculado de acordo com a seguinte fórmula: peso pós-cocção $\times$ 100/peso pré-cocção, expressos em percentuais. O volume aparente foi aferido por meio de uma proveta com uma caneta apropriada e a altura alcançada pela massa foi marcada na pequena fôrma. Após o cozimento da massa, os bolos foram retirados dessas formas, as quais foram preenchidas com água, até a referida marcação. A seguir, despejou-se essa quantidade de água na proveta e fez-se a leitura do volume, expresso em $\mathrm{mL}$. O volume específico foi calculado pela razão entre o volume aparente e o peso pós-cocção das amostras, expresso em mL.g ${ }^{-1}$. Todas as amostras foram resfriadas à temperatura ambiente por 30 minutos, antes da execução das medições.

\subsection{Análise sensorial}

Os bolos selecionados, levando-se em consideração os teores de PSL e margarina que mais influenciaram nas medições, foram submetidos ao teste de aceitabilidade por meio de uma escala hedônica de nove pontos ( 9 = gostei muitíssimo; 5 = não gostei nem desgostei e 1 = desgostei muitíssimo), de acordo com a metodologia proposta por Minim (2006). Para o cálculo do índice de aceitação (IA) do produto, foi adotada a Expressão 1:

$\mathrm{I}(\%)=\mathrm{A} \times 100 / \mathrm{B}$

em que $A=$ nota média obtida para o produto e $B=$ nota máxima dada ao produto. O IA com boa repercussão tem sido considerado $\geq 70 \%$ (DUTCOSKY, 2007).

Participaram do teste, consumidores que receberam as amostras de bolos casualizadas, com codificação de três dígitos aleatórios, acompanhadas de água mineral e ficha para avaliação do produto. O teste foi conduzido em cabines individuais sob iluminação branca. Para que os consumidores participassem, foi necessária a assinatura voluntária do Termo de Consentimento Livre e Esclarecido (TCLE). Foram excluídos os participantes com menos de 18 anos de idade, os que não desejaram assinar o TCLE, aqueles que desistiram de sua participação ou que apresentaram alguma enfermidade no momento da análise. O estudo foi aprovado pelo Comitê de Ética em Pesquisa do Centro de Ciências da Saúde - UFES (n. $\left.{ }^{\circ} 302.657 / 2014\right)$.

\subsection{Avaliação da composição centesimal e da qualidade microbiológica}

A preparação de bolo escolhida por meio da análise sensorial foi analisada quanto à sua composição centesimal, em duplicata, de acordo com a AOAC 
(HORWITZ, 2005). Para este teste, foi analisada também uma amostra controle, sem adição de PSL e com teor de margarina referente ao ponto central do delineamento (9,4 g/100 g). Foram realizadas análises de umidade, extrato etéreo em extrator Soxhlet utilizando-se éter de petróleo, nitrogênio bruto por Kjedahl e resíduo mineral (cinzas). Carboidratos totais foram calculados por diferença: 100 - (umidade + proteínas + extrato etéreo + cinzas + fibra bruta). Para o cálculo do valor energético, determinado em kcal, foi utilizada a seguinte fórmula: valor energético $=(\%$ proteínas $\times 4)+(\%$ carboidratos $\times 4)+(\%$ lipídios $\times 9)$.

Os procedimentos de análise microbiológica foram realizados de acordo com a metodologia da American Public Health Association (APHA), descrita no Compendium of Methods for the Microbiological Examination of Foods (BEUCHAT; COUSIN, 2001). A amostra selecionada por meio da análise sensorial foi analisada ao primeiro dia de processamento e ao $15^{\circ}$ dia após armazenamento, à temperatura ambiente $\left( \pm 28^{\circ} \mathrm{C}\right)$, em ambiente seco e arejado. A amostra foi acondicionada em embalagem de polietileno metalizado de baixa densidade e selada por meio de seladora manual (Sulpack SP 400 TG2).

Foram pesados $25 \mathrm{~g}$ de cada amostra e, em seguida, foram adicionados $225 \mathrm{~mL}$ de água peptonada 0,1\%, previamente esterilizada. A homogeneização foi feita no equipamento stomacher durante $1 \mathrm{~min}$, em velocidade normal. Nessa etapa, foi obtida a diluição $10^{-1}$ da amostra. Em seguida, diluições decimais apropriadas foram preparadas e alíquotas dessas diluições foram transferidas para meios de cultura específicos para a determinação de cada grupo microbiano. O plaqueamento das alíquotas foi realizado em duplicata e o resultado, expresso em unidades formadoras de colônias por grama (UFC. $g^{-1}$ ). Para determinar a presença de fungos filamentosos e leveduras, foi inoculado $0,1 \mathrm{~mL}$ das diluições das amostras sobre a superfície seca de ágar batata glicose $2 \%$, acidificado a $\mathrm{pH} 3,5$. As placas foram incubadas sem inverter, a $25 \pm 1^{\circ} \mathrm{C}$, por 5 a 7 dias. Para coliformes totais e termotolerantes, foi aplicado o Teste do Número Mais Provável, utilizando-se alíquota de $1 \mathrm{~mL}$ das diluições apropriadas das amostras, sendo inoculadas em séries de três tubos contendo $9 \mathrm{~mL}$ de caldo lauril sulfato triptose (LST), com tubo de Duharm invertidos (teste presuntivo), a $35^{\circ} \mathrm{C}$ por 24 a 48 horas. A partir dos tubos com leitura positiva (turvação e formação de gás), foram realizados os testes confirmativos para coliformes totais, em caldo Lactose Bile Verde Brilhante (VB) a $2 \%$, a $35^{\circ} \mathrm{C}$, por 24 a 48 horas e, para coliformes termotolerantes, em caldo Escherichia coli (EC), a $45^{\circ} \mathrm{C}$, por 24 a 48 horas.

Os resultados foram baseados na proporção de tubos com turvação e produção de gás para as três diluições consecutivas, sendo expressos em NMP/g de amostra, após consulta em tabela própria.

\subsection{Análise dos dados}

A significância do modelo aplicado (linear e quadrático) avaliou o efeito da adição de proteína do soro do leite e margarina nas características físicas dos bolos (medições). A significância dos resultados foi testada por meio da análise de variância (teste F), utilizando-se as variáveis independentes de maneira codificada. Os gráficos de Pareto representaram o modelo aplicado, assim como o efeito das variáveis dependentes (proteína do soro do leite e margarina) sobre as variáveis respostas (medições dos bolos).

Os gráficos de superfície de resposta foram desenhados apenas para as respostas significativas, por meio do modelo matemático proposto nos níveis reais (decodificados) das variáveis, mantendo-se a resposta em função do eixo $Z$, com os eixos $X$ e $Y$ representando as variáveis independentes, ao mesmo tempo em que as demais variáveis foram mantidas constantes no ponto central (correspondente ao nível codificado zero). Para as respostas significativas, foi gerada uma equação polinomial de segunda ordem (Equação 2), por meio da regressão aplicada:

$$
\mathrm{Y}=\beta_{0}+\beta_{1} \mathrm{X}_{1}+\beta_{2} \mathrm{X}_{2}+\beta_{11} \mathrm{X}_{1}^{2}+\beta_{22} \mathrm{X}_{2}^{2}+\beta_{12} \mathrm{X}_{1} \mathrm{X}_{2}+\xi
$$

em que: $\mathbf{Y}=$ função resposta; $\mathbf{X}_{\mathbf{1}}, \mathbf{X}_{\mathbf{2}}=$ valores das variáveis independentes; $\beta_{0}=$ coeficiente relativo à interpretação do plano com o eixo resposta; $\beta_{1}, \beta_{2}=$ coeficientes lineares estimados pelo método dos mínimos quadrados; $\beta_{11}, \beta_{22}=$ coeficientes das variáveis quadráticas; $\beta_{12}=$ coeficiente de interação entre as variáveis independentes; $\varepsilon=$ erro experimental.

Os resultados da análise sensorial foram submetidos à análise de variância (ANOVA oneway), seguida do teste Tukey. Os resultados da composição centesimal foram submetidos ao teste $t$ Student. Para todas as avaliações, foi considerada a probabilidade de $5 \%$. Todas as análises estatísticas foram executadas por meio do software Statistica 10.0.

\section{Resultados e discussão}

\subsection{Medições dos bolos}

De acordo com o modelo de regressão aplicado, verificou-se que apenas a altura dos bolos foi influenciada pelos teores de PSL e margarina (Figura 1A e Figura 2). Nota-se que a adição de margarina (até 11,98 g/100 g) foi o fator que mais influenciou a altura dos bolos, reduzindo-a. O mesmo efeito fora observado juntamente com a adição de PSL (até 44,14 g/100 g). Tal evidência pode ser observada por meio da Tabela 1, na qual se verifica que o tratamento com menor teor de margarina (6,72 g/100 g) apresentou maior valor de razão entre a altura inicial e após processamento. Entretanto, observa-se, por meio da equação polinomial gerada para o modelo aplicado (Figura 2), que esta análise deve ser realizada considerando-se a interação 
Efeito da adição de proteína do soro do leite como substituto do trigo na formulação de bolos sem adição de açúcar Soares, J. P. et al.
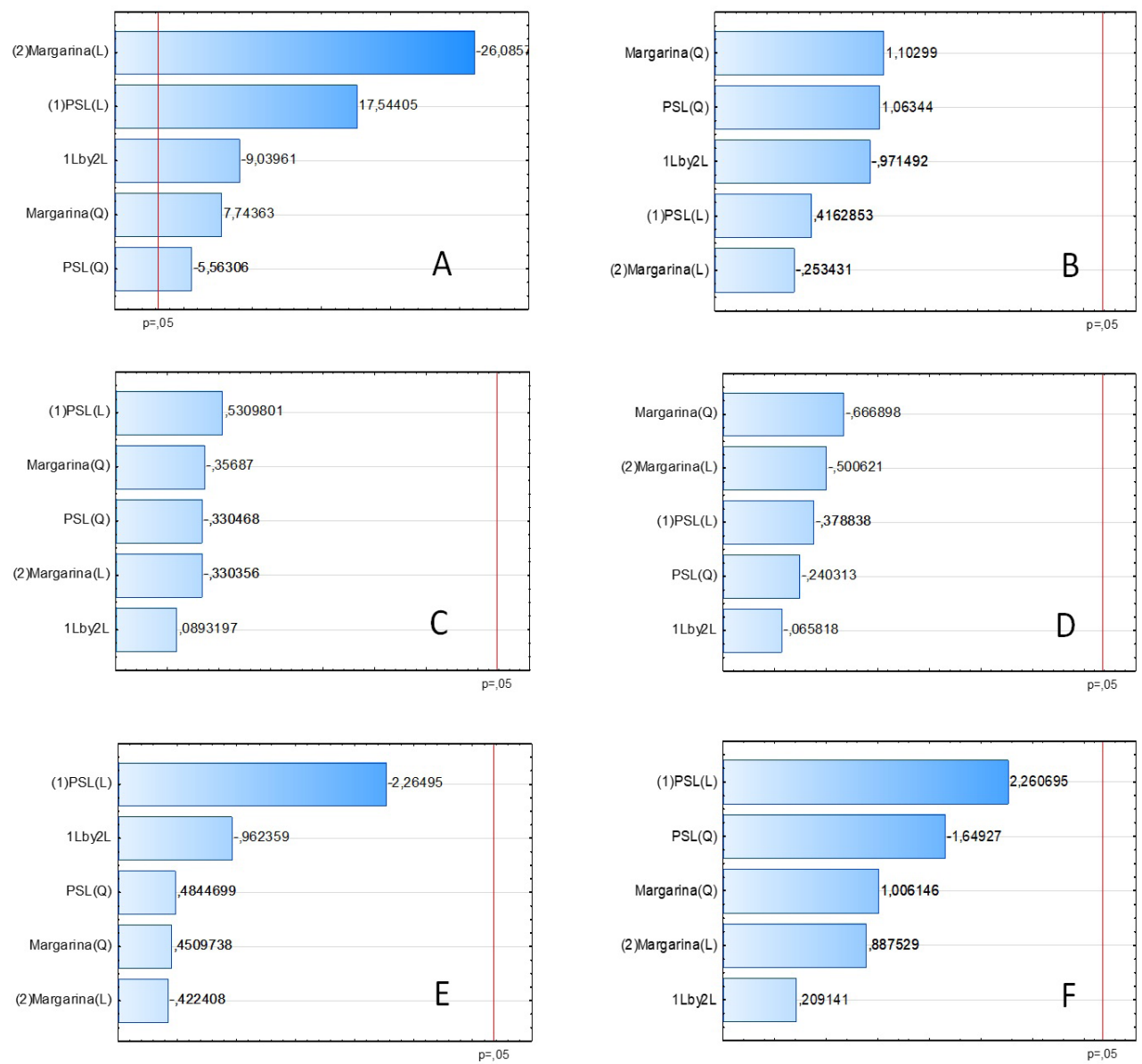

Figura 1. Estimativa dos efeitos lineares $(L)$ e quadráticos $(Q)$ dos teores de proteína do soro do leite (PSL) e margarina nas medições dos bolos. (A) altura; (B) diâmetro; (C) volume aparente; (D) volume específico; (E) fator de expansão; (F) rendimento; 1Lby2L: interação entre as variáveis independentes (1L: proteína do soro do leite e 2L: margarina). Os valores dos efeitos que ultrapassam a linha vermelha são estatisticamente significativos, considerando um intervalo de confiança de $95 \%$.

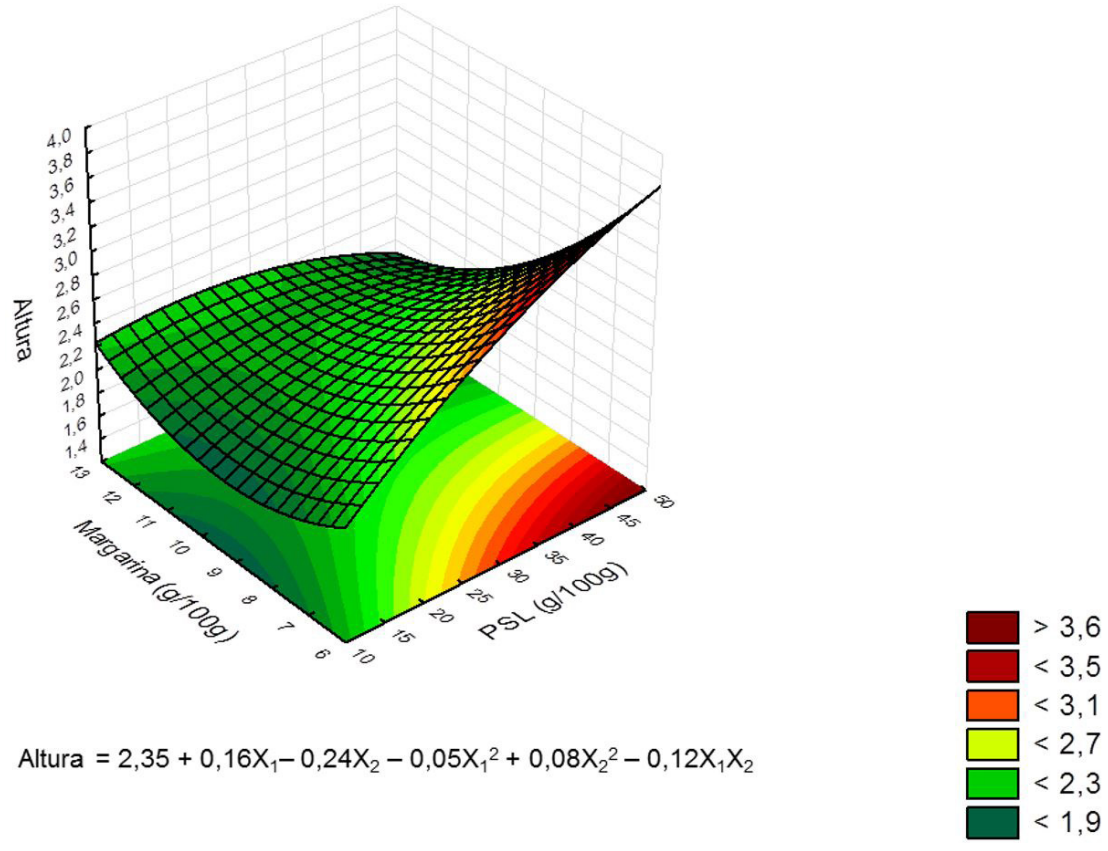

Figura 2. Superfície de resposta e equação polinomial em função da resposta altura dos bolos. 
entre as duas variáveis independentes. O aumento do teor de proteínas oriundas da PSL, bem como o aumento da proporção de lipídios, pode afetar negativamente o crescimento de bolos, em especial pela redução do teor de trigo e, consequentemente, menor conteúdo de glúten, necessário para a expansão durante o processamento dos bolos. Por outro lado, quando avaliada isoladamente, a PSL possui a capacidade de favorecer o crescimento destes produtos, diferentemente da adição de margarina. Em relação às demais variáveis estudadas, nota-se que os teores de PSL e margarina não foram capazes de influenciá-las durante o processamento (Figuras 1B-1F). Destaca-se que, para bolos, é ideal o aumento da altura para que mantenham características sensoriais típicas e desejáveis pelos consumidores, como a aeração e a maciez. O delineamento proposto, bem como os resultados de todas as análises de medições, são evidenciados na Tabela 1.

Morr et al. (2003) ressaltam que a principal exigência para a formação de massas adequada, dependendo do tipo de bolo, é que a mistura tenha a quantidade suficiente de proteínas para que possa se espalhar sobre os componentes da farinha. Caso contrário, a fraca estrutura proteica diminui a retenção de gás na massa e favorece a formação de estrutura compacta e de baixo volume. Foegeding et al. (2006) constataram que a elevação da temperatura no forneamento, a desnaturação proteica e a gelatinização do amido determinam o volume do bolo. No estudo de Zavareze et al. (2010), foi destacado que a adição de proteínas do soro do leite mantém ou até melhora as características de um bolo. Além de conferir aumento de altura em bolos, as proteínas do soro do leite podem melhorar a textura do produto e contribuir nas qualidades sensoriais, em formulações com teor de gordura reduzido.

Apesar de a quantidade de sucralose adicionada às formulações ter sido semelhante para todos os tratamentos, Akesowan (2009) observou, em sua pesquisa, que, conforme se adicionava sucralose à massa, esta perdia volume devido à sua menor capacidade de reter ar. Em contrapartida, a sucralose utilizada neste estudo possui agentes de corpo, como a maltodextrina, as quais, possivelmente, podem favorecer a incorporação de ar nas formulações.

Desta forma, considerando-se que a altura dos bolos foi influenciada pelos teores de PSL e margarina, foram adotados, como critério de seleção, os tratamentos que possuem maior teor de PSL, menor teor de margarina e a combinação dessas duas variáveis. Desta forma, foram selecionados os tratamentos T4 (40 g/100 g de proteína e 7,69 g/100 g de margarina), T6 (44,14 g/100 g de proteína e 9,4 g/100 g de margarina) e T7 (30 g/100 g de proteína e 6,72 g/100 g de margarina), que foram submetidos à análise sensorial.

\subsection{Análise sensorial}

Dentre os 70 consumidores, entre 18 e 36 anos, que participaram da análise sensorial, 97,14\% afirmaram gostar de bolos, sendo que 35,71\% consumiam uma vez por mês e $34,28 \%$ consumiam quinzenalmente. Dentre os consumidores, 92,85\% afirmam que, certamente, gostam de experimentar novos alimentos; note-se que 81,42\% cursavam o Ensino Superior, no momento da análise.

Observa-se que todos os tratamentos apresentaram médias semelhantes para os atributos aparência, cor e aroma, com índices de aceitação próximos ou acima de 80\% (Tabela 2). Para os atributos sabor e textura, destaca-se que o tratamento 7 (contendo $30 \mathrm{~g} / 100 \mathrm{~g}$ de PSL e 6,72 g/100 g de margarina) apresentou maior índice de aceitação. Para este caso, sugere-se que a adição de PSL combinada com a redução do teor de margarina favoreceu estes atributos sensoriais.

Em relação à intenção de compra, observa-se que os consumidores, no geral, tiveram dúvida quanto à aquisição destes produtos. Apenas o tratamento 7 obteve maior média para este item (Tabela 2).

Alguns pesquisadores avaliaram a aceitação de produtos panificados contendo PSL. Marques et al. (2016), ao inserirem PSL na formulação de biscoitos sem adição de açúcar, notaram índices de aceitação semelhantes

Tabela 2. Resultados* da avaliação sensorial de bolos elaborados com diferentes proporções de proteína do soro do leite e margarina.

\begin{tabular}{|c|c|c|c|c|c|c|}
\hline Tratamentos & Aparência & Sabor & Cor & Aroma & Textura & $\begin{array}{c}\text { Intenção de } \\
\text { Compra }\end{array}$ \\
\hline T4 & $\begin{array}{c}7,57^{a} \\
(84,1 \%)\end{array}$ & $\begin{array}{c}6,51^{\mathrm{b}} \\
(72,4 \%)\end{array}$ & $\begin{array}{c}7,74^{a} \\
(86,0 \%)\end{array}$ & $\begin{array}{c}7,40^{a} \\
(82,2 \%)\end{array}$ & $\begin{array}{c}6,34^{\mathrm{b}} \\
(70,5 \%)\end{array}$ & $5,88^{a b}$ \\
\hline T6 & $\begin{array}{c}7,57^{a} \\
(84,1 \%)\end{array}$ & $\begin{array}{c}6,73^{\mathrm{ab}} \\
(74,8 \%)\end{array}$ & $\begin{array}{c}7,67^{a} \\
(85,2 \%)\end{array}$ & $\begin{array}{c}7,08^{a} \\
(78,7 \%)\end{array}$ & $\begin{array}{c}6,37^{b} \\
(70,8 \%)\end{array}$ & $5,48^{b}$ \\
\hline $\mathrm{T} 7$ & $\begin{array}{c}7,72^{a} \\
(85,9 \%)\end{array}$ & $\begin{array}{c}7,27^{a} \\
(80,8 \%)\end{array}$ & $\begin{array}{c}7,72^{\mathrm{a}} \\
(85,9 \%)\end{array}$ & $\begin{array}{c}7,53^{a} \\
(83,5 \%)\end{array}$ & $\begin{array}{c}7,18^{a} \\
(79,8 \%)\end{array}$ & $6,73^{a}$ \\
\hline
\end{tabular}

* Médias (\% - índice de aceitação para os atributos sensoriais). Médias seguidas com mesma letra na mesma coluna não diferiram entre si significativamente, considerando-se um intervalo de confiança de 95\% (Teste Tukey). Tratamentos: T4 (40 g/100 g de proteína e 7,69 g/100 g de margarina); T6 (44,14 g/100 g de proteína e 9,4 g/100 g de margarina) e T7 (30 g/100 g de proteína e 6,72 g/100 g de margarina). 
para os atributos sensoriais, em especial para textura. Silva et al. (2011), em estudo com pães elaborados com soro de leite de vaca, obtiveram resultados que, quando comparados com os obtidos no presente estudo, mostram-se inferiores. Entretanto, os pães elaborados com soro de leite de cabra obtiveram médias muito próximas às aqui evidenciadas. Resultados semelhantes foram obtidos por Gurgel et al. (2011), ao formularem pães de fôrma contendo soro de leite em pó e carbonato de cálcio, como também por Ferrari et al. (2013), após formulação de bolos contendo soro do leite in natura.

Zavareze et al. (2010) avaliaram a adição de soro do leite in natura, concentrado e desidratado em bolos. Os autores destacaram que, em todos os casos, a adição de soro do leite manteve ou melhorou as características dos bolos, sendo que aqueles formulados com soro do leite concentrado e desidratado obtiveram maior preferência.

\subsection{Composição centesimal e análise microbiológica}

Considerando-se que, dentre as amostras avaliadas na análise sensorial, o tratamento 7 obteve melhor aceitação, este foi avaliado quanto à composição centesimal e análise microbiológica, durante o armazenamento. De acordo com os resultados da análise de composição centesimal para o tratamento 7 e para a amostra controle, não foram evidenciadas diferenças significativas entre os teores de umidade, cinzas e lipídios (Tabela 3). Entretanto, observa-se que o tratamento 7 apresentou maior teor de proteínas (17 g/100 g), quando comparado com a amostra controle. Este tratamento também obteve menor teor de carboidratos totais (12 g/100 g), porém não diferiu no valor energético, quando comparado com a amostra controle.
Cabe destacar que o tratamento contendo PSL apresentou um conteúdo de proteínas notavelmente superior aos observados nos estudos de Ferrari et al. (2013), com 7,1 g/100 g, em bolos; Gurgel et al. (2011), com 8,0 g/100 g, em pães de fôrma, e Zavareze et al. (2010), com 13,4 g/100 g, em bolos contendo soro de leite desidratado.

Neste caso, é correto afirmar que o bolo elaborado com proteína do soro do leite, apesar de apresentar valor energético semelhante à amostra controle (sem adição de PSL), apresentou maior teor de proteínas e menor teor de carboidratos totais. Além disso, por se tratar de bolos sem adição de açúcar, são apropriados para o consumo por aqueles que possuem restrições ao consumo de sacarose ou que apenas restringem este ingrediente por opção.

Foi possível observar, por meio dos resultados das análises de coliformes a $45^{\circ} \mathrm{C}$, resultados positivos quanto à qualidade dos produtos, uma vez que não houve crescimento de coliformes em nenhuma amostra, mesmo após o armazenamento durante 15 dias (Tabela 4). De acordo com os resultados obtidos, pode-se considerar que os bolos estão aptos para o consumo, pois estão dentro dos padrões estabelecidos pela legislação vigente (BRASIL, 2001), demonstrando, assim, que foram manipulados de forma adequada. A Portaria n. ${ }^{\circ} 12$ do Ministério da Saúde de 02 de janeiro de 2001 (BRASIL, 2001) não prevê limites para fungos filamentosos e leveduras, recomendando uma análise visual do crescimento destes micro-organismos, os quais não foram observados durante o armazenamento.

Tabela 3. Composição centesimal (média \pm desvio padrão) dos bolos elaborados com proteína do soro do leite e tratamento controle.

\begin{tabular}{ccc} 
Componentes & TC & T7 \\
(g/100 $\mathbf{g}$ - base seca) & $53,00 \pm 11,03^{\mathrm{a}}$ & $57,62 \pm 2,02^{\mathrm{a}}$ \\
Umidade & $3,88 \pm 0,04^{\mathrm{a}}$ & $4,00 \pm 0,03^{\mathrm{a}}$ \\
Cinzas & $7,11 \pm 1,65^{\mathrm{b}}$ & $17,83 \pm 1,09^{\mathrm{a}}$ \\
Proteínas & $9,37 \pm 0,53^{\mathrm{a}}$ & $8,46 \pm 0,66^{\mathrm{a}}$ \\
Lipídios & $26,61 \pm 8,89^{\mathrm{a}}$ & $12,08 \pm 2,42^{\mathrm{b}}$ \\
Carboidratos totais & $219,30 \pm 46,93^{\mathrm{a}}$ & $195,83 \pm 11,26^{\mathrm{a}}$ \\
\hline Valor energético (kcal)
\end{tabular}

Letras iguais na mesma linha significam não haver significância a 5\% de probabilidade (teste t Student); TC (amostra controle contendo farinha de trigo sem substituição e 9,4 g/100 g margarina); 77 (30 g/100 g proteína do soro do leite e 6,72 g/100 g margarina).

Tabela 4. Análise microbiológica do bolo referente ao tratamento 7 (30 g/100 g proteína do soro do leite e 6,72 g/100 g margarina) durante o período de armazenamento.

\begin{tabular}{cccc} 
Dia & $\begin{array}{c}\text { Coliformes totais } \\
\left(\mathbf{3 5}{ }^{\circ} \mathbf{C}\right)\end{array}$ & $\begin{array}{c}\text { Coliformes termotolerantes } \\
\left(\mathbf{4 5}{ }^{\circ} \mathbf{C}\right)\end{array}$ & $\begin{array}{c}\text { Fungos filamentosos e } \\
\text { leveduras }\end{array}$ \\
$1^{\circ}$ & $<3,0 \mathrm{NMP} / \mathrm{g}$ & $<3,0 \mathrm{NPM} / \mathrm{g}$ & $1,0 \times 10^{3} \mathrm{UFC} / \mathrm{g}$ \\
$15^{\circ}$ & $<3,0 \mathrm{NMP} / \mathrm{g}$ & $<3,0 \mathrm{NPM} / \mathrm{g}$ & $2,0 \times 10^{4} \mathrm{UFC} / \mathrm{g}$ \\
\hline
\end{tabular}

NMP: número mais provável; UFC: unidades formadoras de colônias. 
Efeito da adição de proteína do soro do leite como substituto do trigo na formulação de bolos sem adição de açúcar Soares, J. P. et al.

\section{Conclusão}

A adição de margarina até a concentração máxima aplicada neste estudo foi capaz de reduzir a altura dos bolos. A adição de proteína do soro do leite também foi capaz de produzir o mesmo efeito, porém em proporções menores. Entretanto, quando avaliada de forma isolada, por meio do modelo de regressão, esta matéria-prima é capaz de favorecer o aumento da altura, nestes produtos. O tratamento contendo proporção intermediária de proteína do soro do leite (30 g/100 g) e o menor teor de margarina $(6,72 \mathrm{~g} / 100 \mathrm{~g})$ obteve melhor aceitação e intenção de compra. Além disso, apresentou maior teor de proteínas e menor teor de carboidratos. As condições microbiológicas do referido tratamento foram satisfatórias, atendendo ao padrão microbiológico especificado na legislação vigente, mesmo após 15 dias de armazenamento.

Considerando-se as condições experimentais deste estudo, sugere-se que, quando for feita a adição de proteína do soro do leite, sejam utilizadas menores proporções de margarina.

\section{Agradecimentos}

À empresa Probiótica e à empresa Linea, pela doação das matérias-primas. À Pró-Reitoria de Pesquisa e Pós-graduação (PRPPG) da Universidade Federal do Espírito Santo.

\section{Referências}

AKESOWAN, A. Quality of reduced-fat chiffon cakes prepared with erythritol-sucralose as replacement for sugar. Pakistan Journal of Nutrition, v. 8, n. 9, p. 1383-1386, 2009. http://dx.doi. org/10.3923/pjn.2009.1383.1386.

AMERICAN ASSOCIATION OF CEREAL CHEMISTS - AACC. Approved methods of the American Association of Cereal Chemists. 10th ed. St. Paul: AACC, 2000.

ASSOCIAÇÃO BRASILEIRA DAS INDÚSTRIAS DE MASSAS ALIMENTÍCIAS - ABIMAPI. Estatísticas de pães e bolos industrializados. São Paulo: ABIMAPI, 2016. Disponível em: <http://www.abimapi.com.br/estatistica-paes-bolos.php>. Acesso em: 11 abr. 2017.

BEUCHAT, L. R.; COUSIN, M. A. Yeasts and molds. In: DOWNES, F. P.; ITO, K. (Ed.). Compendium of methods for the microbiological examination of foods. 4th ed. Washington: American Public Health Association, 2001. http://dx.doi.org/10.2105/9780875531755ch20.

BOX, G. E. P.; DRAPER, N. R. Empirical model-building and response surfaces. New York: John Wiley \& Sons, 1987. 669 p.

BRASIL. Ministério da Saúde. Resolução RDC n 12 , de 2 de janeiro de 2001. Dispõe sobre o regulamento técnico sobre padrões microbiológicos para alimentos. Diário Oficial [da] República Federativa do Brasil, Brasília, DF, 12 jan. 2001. Disponível em: <http://portal.anvisa.gov.br/documents/33880/2568070/
RDC_12_2001.pdf/15ffddf6-3767-4527-bfac-740a0400829b>. Acesso em: 21 dez. 2016.

DUTCOSKY, S. D. Análise sensorial de alimentos. 2. ed. Curitiba: Champagnat, 2007. 239 p.

ESTELLER, M. S. Fabricação de pães com reduzido teor calórico e modificações reológicas ocorridas durante o armazenamento. 2004. 248 f. Dissertação (Mestrado em Tecnologia de Alimentos)-Faculdade de Ciências Farmacêuticas, Universidade de São Paulo, São Paulo, 2004.

FERRARI, A. S.; BALDONI, N. R.; AZEREDO, E. M. C. Análise sensorial e físico-química de produtos elaborados à base de soro de leite. Revista da Universidade Vale do Rio Verde, v. 11, n. 1, p. 216-223, 2013

FOEGEDING, E. A.; LUCK, P. J.; DAVIS, J. P. Factors determining the physical properties of protein foams. Food Hydrocolloids, v. 20 , n. 2-3, p. 284-292, 2006. http://dx.doi.org/10.1016/j. foodhyd.2005.03.014.

GOHARA, A. K.; SOUZA, A. H. P.; ZANQUI, A. B.; SOUZA, N. E.; VISENTAINER, J. V.; MATSUSHITA, M. Chemometric tools applied to the development and proximal and sensory characterization of chocolate cakes containing chia and azuki. Acta Scientiarum. Technology, v. 36, n. 3, p. 537-543, 2014. http://dx.doi.org/10.4025/actascitechnol.v36i3.19298.

GURGEL, C. S. S.; MACIEL, J. F.; FARIAS, L. R. G.; COSTA, M. J. C.; MOREIRA, R. T. Consumer acceptance and purchase intention of bread enriched with milk serum and calcium carbonate. Revista do Instituto Adolfo Lutz, v. 70, n. 3, p. 283-289, 2011.

HORWITZ, W. (Ed.). Official methods of the Association of Official Agriculture Chemists. Washington: AOAC, 2005.

KÖVESI, B.; SIFFERT, C.; CREMA, C.; MARTINOLI, G. 400 g: técnicas de cozinha. São Paulo: Companhia Editora Nacional, 2007. 576 p.

LAM, R. S.; NICKERSON, M. T. The effect of $\mathrm{pH}$ and temperature pre-treatments on the physicochemical and emulsifying properties of whey protein isolate. Lebensmittel-Wissenschaft + Technologie, v. 60, n. 1, p. 427-434, 2015. http://dx.doi. org/10.1016/j.lwt.2014.07.031.

MARQUES, G. A.; SÃO JOSÉ, J. F. B.; SILVA, D. A.; SILVA, E. M. $M$. Whey protein as a substitute for wheat in the development of no added sugar cookies. Lebensmittel-Wissenschaft + Technologie, v. 67, p. 118-126, 2016. http://dx.doi.org/10.1016/j. Iwt.2015.11.044.

MINIM, V. P. R. Análise sensorial: estudos com consumidores. Viçosa: Universidade Federal de Viçosa, 2006. cap. 1 e 3.

MORR, C. V.; HOFFMANN, W.; BUCHHEIM, W. Use of applied air pressure to improve the baking properties of whey protein isolates in angel food cakes. Lebensmittel-Wissenschaft + Technologie, v. 36, n. 1, p. 83-90, 2003. http://dx.doi.org/10.1016/ S0023-6438(02)00187-1. 
Efeito da adição de proteína do soro do leite como substituto do trigo na formulação de bolos sem adição de açúcar Soares, J. P. et al.

OLIVEIRA, D. F.; BRAVO, C. E. C.; TONIAL, I. B. Soro de leite: um subproduto valioso. Revista do Instituto de Laticínios Cândido Tostes, v. 67, n. 385, p. 64-71, 2012. http://dx.doi. org/10.5935/2238-6416.20120025.

PINHEIRO, M. V. S.; PENNA, A. L. B. Substitutos de gordura: tipos de aplicações em produtos lácteos. Alimentos e Nutrição, v. 15, n. 2 , p. 175-186, 2004.

SILVA, C. A.; GOMES, J. P.; SILVA, F. L. H.; MELO, E. S. R. L.; CALDAS, M. C. S. Utilização de soro de leite na elaboração de pães: estudo da qualidade sensorial. Revista Brasileira de Produtos Agroindustriais, v. 13, n. 4, p. 355-362, 2011. http:// dx.doi.org/10.15871/1517-8595/rbpa.v13n4p355-362.
SILVA, J. V. Desenvolvimento de bolos, com e sem adição de açúcar, a partir da substituição parcial da farinha de trigo por farinha de casca e semente de abóbora (Curcubita moschata). 2011. 111 f. Dissertação (Mestrado em Ciência e Tecnologia de Alimentos)-Universidade Federal de Sergipe, São Cristóvão, 2011. VOORPOSTEL, C. R.; DUTRA, M. B. L.; BOLINI, H. M. A. Sensory profile and drivers of liking for grape nectar among smoker and nonsmoker consumers. Food Science and Technology, v. 34, n. 1, p. 164-173, 2014.

ZAVAREZE, E. R.; MORAES, K. S.; SALAS-MELLADO, M. L. M. Qualidade tecnológica e sensorial de bolos elaborados com soro de leite. Ciência e Tecnologia de Alimentos, v. 30, n. 1, p. 100-105, 2010 